\title{
ESTUDO DAS INUNDAÇÕES NA CIDADE DE ALEGRETE, RIO GRANDE DO SUL: PROBABILIDADE E ESPACIALIZAÇÃO DO PERIGO
}

\author{
Daniel Junges Menezes \\ Secretaria de Coordenação e Governança do Patrimônio da União - Ministério da Economia, DF, Brasil \\ danieljunges@hotmail.com \\ Luís Eduardo de Souza Robaina \\ Universidade Federal de Santa Maria, Pós-Graduação em Geografia, Santa Maria, RS, Brasil \\ lesrobaina@yahoo.com.br \\ Romario Trentin \\ Universidade Federal de Santa Maria, Pós-Graduação em Geografia, Santa Maria, RS, Brasil \\ romario.trentin@gmail.com
}

\begin{abstract}
RESUMO
As inundações são o perigo natural mais comum, afetando mais pessoas e causando mais danos do que qualquer outro tipo de perigo. Este trabalho apresenta uma metodologia para determinar a probabilidade e a espacialização das áreas sob ameaça de inundação na cidade de Alegrete, que é um dos municípios do estado com maior quantidade de registros de inundações. A análise da dinâmica espacial das inundações se deu a partir da projeção dos níveis d'água sobre o modelo digital do terreno, estabelecendo uma relação entre cota registrada no rio e cota altimétrica no terreno modelado, sendo então estimadas as áreas atingidas e estabelecidas como suscetíveis a inundação. Em Alegrete as áreas sujeitas a processos de inundação configuram a expressiva porção de $30,8 \%$ da área urbana, mas considerando as áreas efetivamente ocupadas, representam um pouco mais de $3 \%$. Esse número é muito importante, pois as inundações com tempo de retorno de 20 anos atingem 52 ha do total da área edificada. A elevada área que pode ser afetada e a significativa porção já afetada resultam em uma complexa gestão e planejamento da ocupação urbana.
\end{abstract}

Palavras-chave: Alegrete. Inundações. Perigo. Mapeamento.

\section{FLOOD STUDY IN THE ALEGRETE CITY, RIO GRANDE DO SUL: PROBABILITY AND SPACIALIZATION OF THE HAZARD}

\begin{abstract}
Floods are the most common natural hazard, affecting more people and causing more damage than any other type of hazard. This work presents a methodology to determine the probability and spatialization of flooded areas in Alegrete city, which is one of the city in the state with the highest amount of flood records. The analysis of the spatial dynamics of the floods was based on the projection of water levels on the digital terrain model. A relation was established between quota recorded in the river and altimetric quota in the terrain modeled, being estimated the areas reached and established as susceptible to flood. In Alegrete, the areas subject to flooding processes represent the expressive portion of $30.8 \%$ of the urban area. Considering the effectively occupied areas, they represent a little more than $3 \%$. This number is very important because the floods with a return time of 20 years, reach 52ha of the total built area. The high area that can be affected and the significant portion already affected results in a complex management and planning of the urban occupation.
\end{abstract}

Keywords: Alegrete. Floods. Hazard. Mapping. 


\section{INTRODUÇÃO}

Os eventos naturais ocorrem de forma independente das atividades humanas, mas por outro lado, para efeitos práticos, grande parte do sistema social também pode ser considerada como operante, de forma independente dos eventos naturais. A Geografia aborda as interações entre sociedade e natureza de forma espacialmente localizada e atribui valor aos lugares, aos seus habitantes e às suas características, para compreensão dos desastres naturais, e estuda estes processos observando as suas consequências (REBELO, 2008, CUTTER et al., 2008)

Para Marandola Junior e Hogan (2004) e Burton et al. (1993) nem todos os fenômenos naturais são considerados perigosos, mas apenas aqueles que estão ocorrendo em áreas ocupadas pelo homem, gerando danos e perdas. Portanto, um evento perigoso não é natural em si, mas trata-se de um evento que ocorre na interface sociedade-natureza (MARANDOLA JUNIOR. e HOGAN, 2004, p.98). Dessa forma, a terminologia "perigo" (ou ameaça) indica condição com potencial para causar uma consequência desagradável.

Conforme Westen et al. (2006), o perigo pode ser expresso como a probabilidade de ocorrência dentro de um período de referência. Este se dá em função da probabilidade espacial, relacionada a fatores ambientais estáticos, que remetem às características do terreno e a probabilidade temporal, relacionada indiretamente a alguns fatores ambientais e diretamente a fatores dinâmicos, como variáveis hidrológicas.

Para Julião et al. (2009) o perigo indica o processo (ou ação) natural, tecnológico ou misto, suscetível de produzir perdas e danos identificados. A suscetibilidade remeta à propensão de uma área para ser afetada por um determinado perigo, em tempo indeterminado, sendo avaliada através dos fatores de predisposição para a ocorrência dos processos ou ações.

A conceituação clássica do glossário da Defesa Civil (CASTRO, 1998) define perigo como "qualquer condição potencial ou real que pode vir a causar morte, ferimento ou dano à propriedade. A tendência moderna é substituir o termo por ameaça. Por sua vez, a "ameaça" é entendida pela International Strategy Disaster Reduction - ISDR (UNISDR, 2009) como "Prenúncio ou indício de um evento desastroso".

Portanto, nesse trabalho consideram-se áreas de perigo as porções sujeitas a inundações, portanto suscetíveis e que, ocupadas, podem causar danos em função da sua ocorrência.

As inundações são o perigo natural mais comum, afetando mais pessoas e causando mais danos do que qualquer outro tipo de perigo (KUSKY, 2008). Conforme Eckhardt (2008) a inundação está associada ao excesso de volume de água, que não drenado pelo canal principal (leito menor), inunda as áreas ribeirinhas (leito maior ou planície de inundação).

Este trabalho apresenta como objetivo o desenvolvimento de uma metodologia para determinar a probabilidade e a espacialização das áreas sob ameaça de inundação na cidade de Alegrete/RS. Dentre os municípios gaúchos que apresentam uma grande recorrência e uma grande quantidade de registros de inundações, está o município de Alegrete (Robaina et al., 2013; Menezes e Sccoti, 2013), que tem a cidade posicionada às margens do rio Ibirapuitã, junto ao médio curso da bacia hidrográfica com coordenadas UTM 6700000 a 67060000 e 613500 a 622000 Fuso 21S. Na Figura 1 é apresentado o mapa de localização da cidade de Alegrete com a divisão dos bairros e a rede de drenagem da cidade.

Os custos relacionados as inundações são diretos como a perda de móveis e utensílios das residências, problema nas vias públicas e a veiculação hídrica de doenças. Os custos indiretos se relacionam a depreciação de moradias e bairros, limpeza de logradouros e propriedades e assistência a desalojados. 
Figura 1 - Localização da área urbana de Alegrete com a divisão dos bairros.

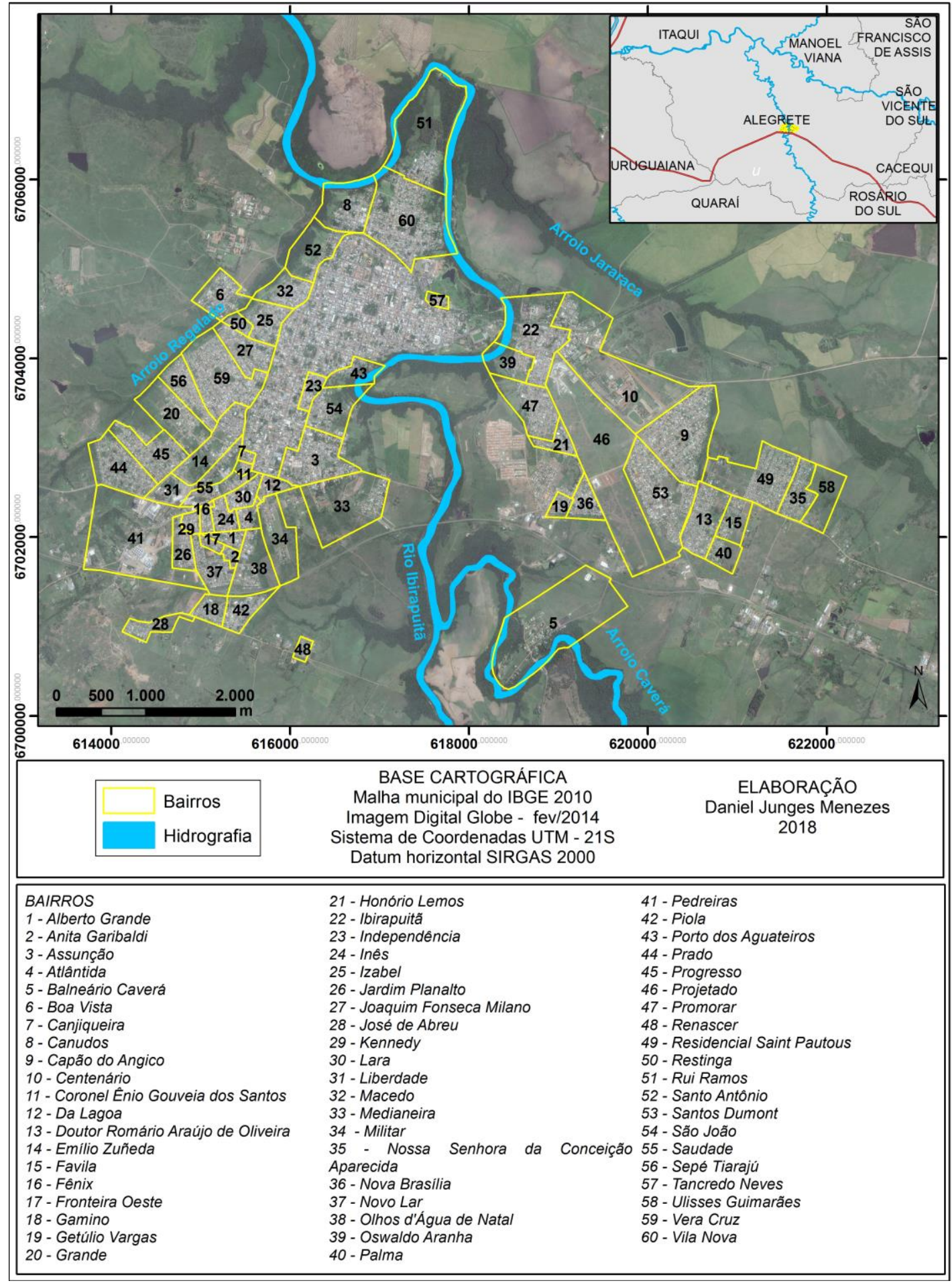

Fonte - os autores

\section{PROCEDIMENTOS METODOLÓGICOS}

A base cartográfica do trabalho baseou-se no Modelo Digital do Terreno (MDT), que foi gerado a partir da interpolação de curvas de nível com equidistância de 5 metros, rede hidrográfica (em feições do tipo polígono e do tipo linha), limite da área urbana, além dos pontos obtidos em levantamento planialtimétrico nas áreas que margeiam o rio lbirapuitã. 
As curvas de nível, a hidrografia e o limite da área urbana foram obtidos junto ao setor de topografia da Prefeitura Municipal de Alegrete, disponibilizados na extensão $d w g$, convertido para o formato shapefile e atribuído sistema de coordenadas métricas (UTM) e projeção no datum horizontal SIRGAS 2000 aos arquivos.

O levantamento planialtimétrico foi realizado durante os trabalhos de campo, em que foram percorridas áreas adjuntas ao rio Ibirapuitã e seus tributários, os arroios Regalado, Jararáca e Caverá, totalizando a coleta de aproximadamente 150 pontos utilizando os receptores GNSS Ruide R90T (precisão horizontal de $5 \mathrm{~mm}+0,5 \mathrm{ppm}$ e precisão vertical de $10 \mathrm{~mm}+0,5$ ppm, quando pós-processado) e Promark 3 Ashtech (precisão horizontal e vertical de $5 \mathrm{~mm}+1$ ppm, quando pós- processado).

A etapa seguinte consistiu no pós-processamento dos pontos coletados, a partir do software GNSS Solutions ${ }^{\circledR}$ (V. 3.80.8) - (ASHTECH,2006), licenciado para o Laboratório de Geologia Ambiental da UFSM. A estação base utilizada para o pós-processamento dos pontos foi a estação de Alegrete/RS (RSAL, Código Internacional 94048) localizada nas coordenadas -2947’22,0036”S e -5546’7,8230”W, altitude elipsoidal de 117,21 m e altura ortométrica de 105,22 m, fazendo parte da Rede Incra de Bases Comunitárias do GNSS - RIBaC.

O MDT foi gerado a partir do interpolador Topo to Raster disponível no ArcToolbox do software ArcGIS® (Arc Map 10.1) desenvolvido pela (ESRI, 2012), licenciado para o Laboratório de Geologia Ambiental da UFSM. A análise da dinâmica espacial das inundações se deu a partir da projeção dos níveis d'água sobre o modelo digital do terreno, estabelecendo uma relação entre cota registrada no rio e cota altimétrica no terreno modelado, sendo então estimadas as áreas atingidas e estabelecidas como suscetíveis à inundação (Figura 2).

Figura 2 - Medições dos níveis do rio junto às réguas da margem.

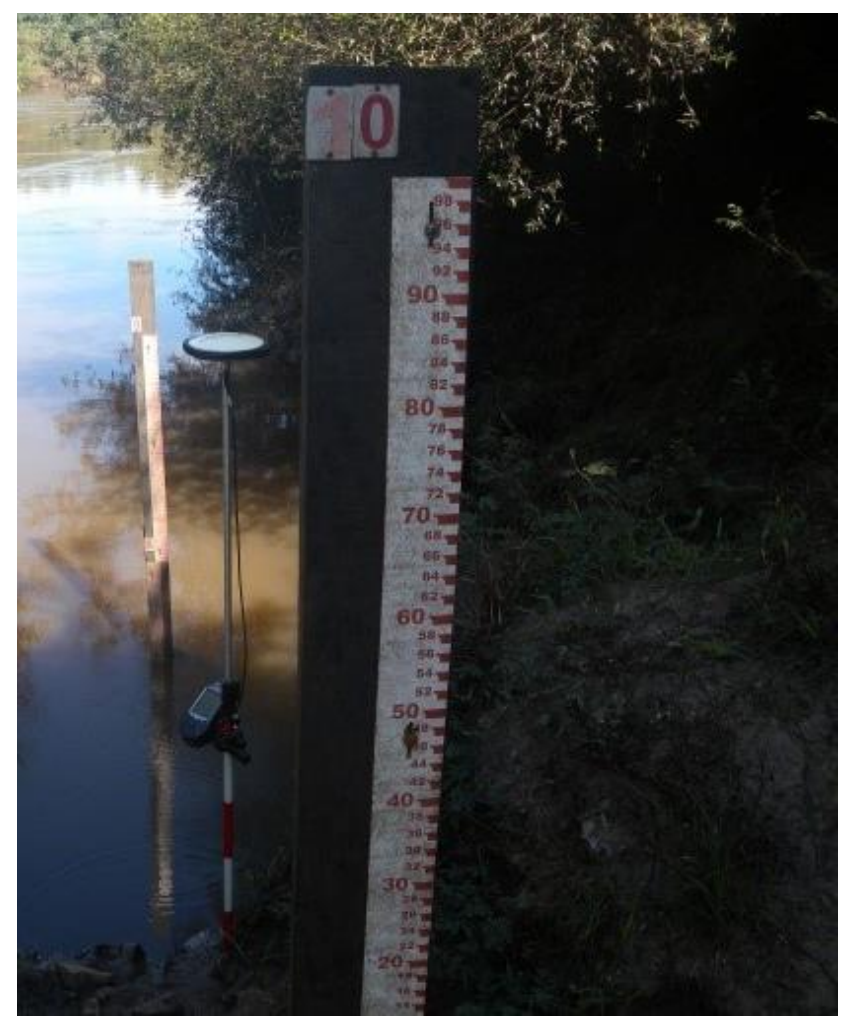

Fonte - Trabalho de campo, janeiro de 2016. Org.: os autores, 2018.

Utilizando funcionalidades do Excel (licenciado para o Laboratório de Geologia Ambiental da UFSM) e Past (software livre), resíduos foram analisados e obtidas medidas de dispersão, sendo a significância estatística obtida através do teste t-Student, com intervalo de confiança de $95 \%(\alpha<0,05)$, estatística utilizada para pequenas amostras. As cotas medidas e as cotas padronizadas a partir da régua apresentaram coeficiente de determinação $\left(r^{2}\right)$ que é igual ao coeficiente de correlação ( $r$ ) elevado ao

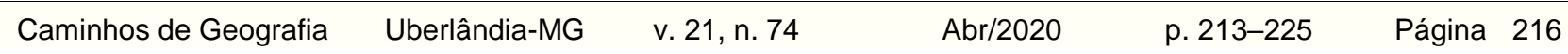


quadrado. A análise dos resíduos (Tabela 1) apontou um erro médio de 0,02 m, erro padrão de 0,03 m e desvio padrão de cerca de $0,10 \mathrm{~m}$.

O intervalo de confiança de $95 \%$ do t- Student para 11 amostras foi de 0,069 m, apontando resíduos entre $-0,045$ e $0,09 \mathrm{~m}$, respectivamente, como limites inferior e superior. Estes se referem aos pontos finais do intervalo de confiança, estabelecendo uma faixa de 0,138 m como medida dessa incerteza em relação à média.

Tabela 1 - Sumário estatístico - Relação nível linimétrico e cota altimética.

\begin{tabular}{c|c}
\hline Estatística & Valores $(\mathrm{m})$ \\
\hline Variância & 0,011 \\
\hline Desvio Padrão & 0,103 \\
\hline Erro Padrão & 0,031 \\
\hline Int de Confiança 95\% & 0,069 \\
\hline Média & 0,025 \\
\hline Limite + & 0,094 \\
\hline Limite - & $-0,045$ \\
\hline Amplitude (+-) & 0,138 \\
\hline
\end{tabular}

Fonte - Os autores, 2018.

Os graus de perigo foram estabelecidos em função dos tempos de retorno (probabilidade de ocorrência) e cotas que marcam estas inundações (severidade).

A análise de tempos de retorno das inundações, estabelecida a partir da série histórica de cotas do rio Ibirapuitã, permitiu hierarquizar a ocorrência conforme a probabilidade cumulativa e consequente probabilidade de excedência, sendo então estimados os valores entre 0 a 1 para ocorrência de inundações (onde 1 é a probabilidade máxima de ocorrência e 0 a de não ocorrência). Estes índices foram estabelecidos para os seguintes tempos de retorno (TR) em anos: TR2, TR5, TR20, TR50 e maior que 50 anos.

A severidade das inundações para a área urbana de Alegrete esteve associada à altimetria de 71,83 m (correspondente à cota linimétrica de 5,34 metros, o menor valor dentre as máximas anuais registradas) e à altimetria de 81,7 (linha de inundação medida). A amplitude destes valores $(9,92 \mathrm{~m})$ corresponde à amplitude do limite vertical de uma inundação e então a severidade deste processo. Da mesma forma, a amplitude destes valores foi padronizada para valores de 0 a 1 (onde 1 é a altura máxima da inundação e 0 a mínima), correspondendo à severidade.

Deste modo, estabeleceu-se para as inundações um índice de perigo (entre 0 e 1), considerando como elementos o tempo de retorno (expresso em probabilidade) e magnitude (severidade). Esta proposta metodológica pode ser expressa a partir da seguinte fórmula:

$$
P=[p(T R)]+[S p]
$$

Onde: Perigo "P" é a soma da probabilidade "p" associada a um determinado Tempo de Retorno "TR" e da severidade padronizada "Sp", sendo $P=(0 \leq P \leq 1)$.

Critério semelhante foi adotado para as áreas junto ao arroio Caverá, onde não existindo medições linimétricas, foram estimadas recorrências em função de observações de campo, sendo estimadas probabilidades para as inundações com magnitude igual aos eventos recentes, dos anos de 2009 e 2017. Foi considerada para severidade a cota altimétrica de $76,5 \mathrm{~m}$, junto ao arroio e a cota de inundação de 2015 medida no perfil Caverá, de $83,75 \mathrm{~m}$. Para os processos associados à porção montante do arroio Regalado, foram utilizados índices arbitrários de 0,1 a 0,35, conforme a distância do canal, onde de

$\begin{array}{llllll}\text { Caminhos de Geografia } & \text { Uberlândia-MG } & \text { v. 21, n. } 74 & \text { Abr/2020 } & \text { p. 213-225 } & \text { Página } 217\end{array}$


maneira geral os processos caracterizam-se pela grande recorrência, mas pouca severidade, em relação às inundações do rio Ibirapuitã.

\section{RESULTADOS}

Estabelecido o levantamento altimétrico, obtido o modelo digital do terreno da área urbana de Alegrete e estabelecida a associação das cotas do rio Ibirapuitã com cotas respectivas altimétricas, foi possível espacializar as inundações projetadas sobre o terreno modelado considerando-se diferentes magnitudes e frequências

Como atributo prévio para a espacialização das áreas inundáveis, tomou-se a cota de $82 \mathrm{~m}$ na área urbana de Alegrete, em acordo com o Plano Diretor, Lei no 2.679, de 05 de junho de 1996 do Município de Alegrete, que foi atualizado para se adequar às diretrizes contidas no Estatuto da Cidade (Lei № 10.257, de 10 de julho de 2001) (BRASIL, 2001).

O contexto deste levantamento esteve associado à inundação de dezembro do ano de 2015 (Figura 3), considerada um evento extremo, em termos de magnitude e recorrência pela Defesa Civil e moradores. O Relatório Gerencial de Danos Informados do Sistema Nacional de Proteção e Defesa Civil (SINPDEC) estimou 1.159 desabrigados, 3.841 desalojados, com um total de 5.000 afetados diretos.

Figura 3 - Inundação do rio Ibirapuitã sobre a área urbana de Alegrete - 21/25 de dezembro de 2015.

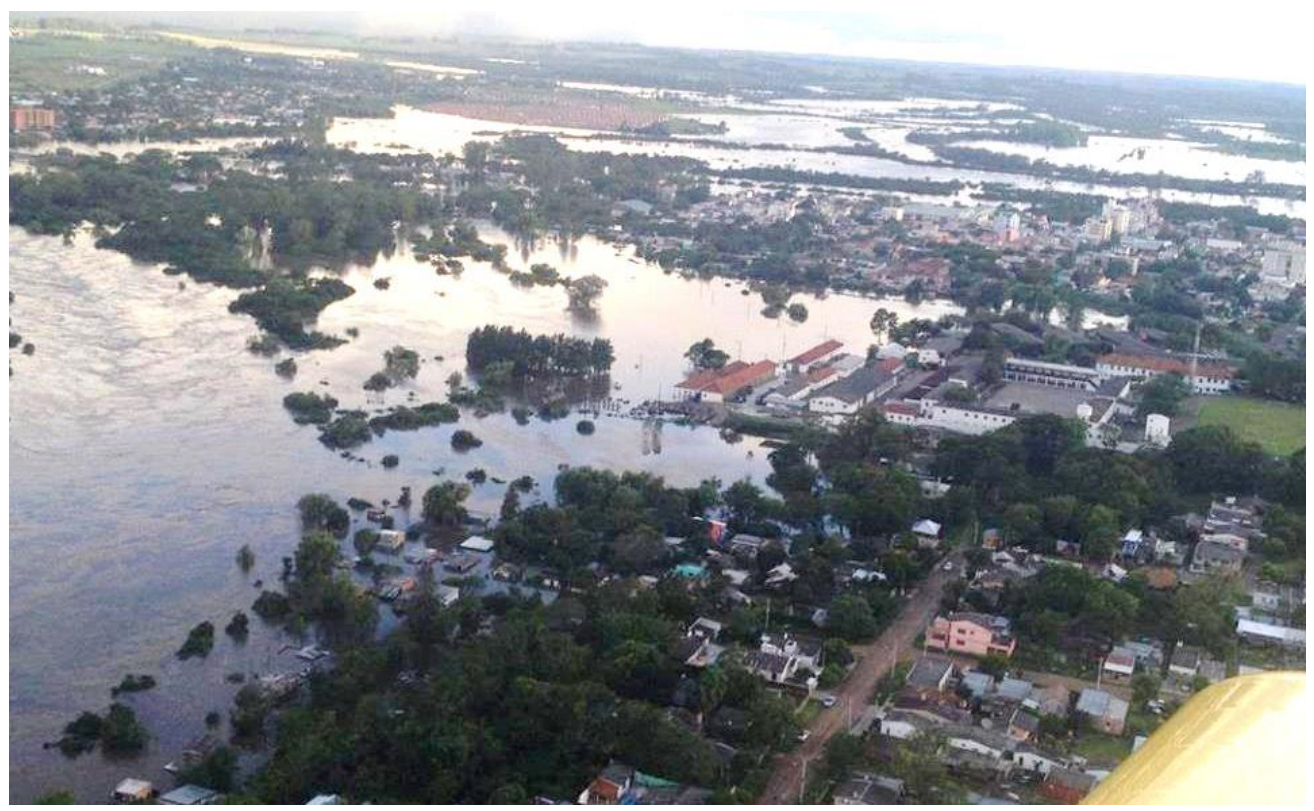

Fonte - Prefeitura Municipal de Alegrete, 2015.

A partir do levantamento por perfis, foram estimadas cotas altimétricas para o alcance máximo das águas no evento de 2015, sendo obtido uma cota de $81,75 \mathrm{~m}$.

Os trabalhos de campo permitiram acrescer áreas em relação à cota de $82 \mathrm{~m}$ em porções junto ao arroio Caverá, tributário mais à jusante ao rio Ibirapuitã. Para estabelecer relações de recorrência foram utilizadas, neste caso específico, cotas associadas aos eventos registrados nos dias 25/11/2009 e 18/09/2017, além do evento de 2015.

Os processos de inundação do rio Ibirapuitã foram divididos em sete trechos, a serem citados: trecho meandro Norte, trecho meandro Oeste, trecho meandro Leste, trecho Sul, trecho Caverá, trecho Jararáca e trecho Regalado/jusante. 
Para o zoneamento das áreas de perigo de inundação foram utilizadas as imagens de satélites obtidas gratuitamente a partir do aplicativo SAS Planet, sendo exportadas imagens GeoEye, datadas de agosto de 2016 e fevereiro de 2018, com resolução espacial de $0,5 \mathrm{~m}$, já mosaicadas e georreferenciadas no sistema de coordenadas UTM $-21 \mathrm{~S}$.

A área urbanizada e o sistema viário foram interpretados com base nas imagens de alta resolução (cor verdadeira) e aplicação de técnicas de fotointerpretação, que mesclam a distinção e associação visual de formas, cores e texturas. A obtenção de um arquivo de estrutura vetorial se deu por meio da criação de poligonais, utilizando-se as ferramentas de vetorização e edição disponíveis no software ArcGIS 10.1.

Da mesma forma, foram delimitadas as áreas de edificações visíveis na escala de 1:2.000 e que apresentam continuidade física até serem cessadas por terrenos ou áreas cuja ocupação não seja permanente ou de uso não urbano (cobertura vegetal, campo natural e antrópico, culturas e corpos d'água). Para a representação na cartografia síntese adota-se a designação genérica de área urbanizada/edificada, que compreende os vários tipos identificados.

Os dados obtidos indicam que as áreas sujeitas, de alguma forma, a processos de inundação configuram a expressiva porção de $30,8 \%$ da área total correspondente à área urbana de Alegrete. A partir do mapa de suscetibilidade a inundações (Figura 4) podemos observar a distribuição espacial das áreas inundáveis. Essas áreas totalizam aproximadamente 1.002,5 ha, considerando as áreas delimitadas pela cota de $82 \mathrm{~m}$ e ainda os processos associados aos arroios Regalado e Caverá, que juntos compõem aproximadamente $2,7 \%$ do montante desta área.

Quando se considera as áreas edificadas, o processo de inundação afeta 11,9\%, totalizando aproximadamente 119,16 ha, um pouco superior a $3 \%$ do total da área urbana, considerando os adensamentos urbanos junto ao rio Ibirapuitã, arroio Caverá e ainda as áreas que são afetadas em função de processos nas porções jusante e montante do arroio Regalado.

As formas recortadas do rio Ibirapuitã, junto à área urbana de Alegrete, implicam em grandes áreas inundáveis junto às porções côncavas. Além disso, observam-se na área urbana, setores das áreas adjacentes aos canais de drenagem afluentes do Ibirapuitã, que se encontram mais afetados pela urbanização. $\mathrm{O}$ arroio Regalado apresenta-se assoreado e está associado a uma significativa área inundável.

$\mathrm{Na}$ análise do grau de perigo, consideram-se os tempos de retorno TR2, TR5, TR 20, T50 e superior a 50 anos. Na Tabela 2 observa-se a extensão de áreas afetadas para cada condição de tempo de retorno. $\mathrm{A}$ distribuição espacial é apresentada no mapa da Figura 5.

Tabela 2 - Tempos de retorno definidos nos graus de perigo de inundação.

\begin{tabular}{c|c|c|c|c}
\hline Tempo de retorno & Cota linimétrica $(\mathrm{m})$ & Cota altimétrica $(\mathrm{m})$ & Área afetada (ha) & Área afetada (\%) \\
\hline TR 2 & 11,2 & 77,69 & $475,1(475,1)$ & $47,38 \%-47,38 \%$ \\
TR 5 & 12,7 & 79,19 & $151,4(626,5)$ & $15,10 \%-62,48 \%$ \\
TR 20 & 13,872 & 80,36 & $222,1(848,6)$ & $22,15 \%-84,63 \%$ \\
TR 50 & 14,412 & 81,01 & $51,3(899,9)$ & $5,12 \%-89,75 \%$ \\
TR $>50$ & $>14,4$ & $<82$ & $77,2(977,1)$ & $7,70 \%-97,45 \%$ \\
Processos & - & 82 ou mais & 25,4 & $2,54 \%$ \\
associados & & & & \\
(Somente Regalado) & & - & 1002,5 & $100 \%$ \\
\hline Total & - & &
\end{tabular}

Fonte - Os autores, 2018. 
Figura 4 - Mapa de áreas suscetíveis a inundações na área urbana de Alegrete - RS.

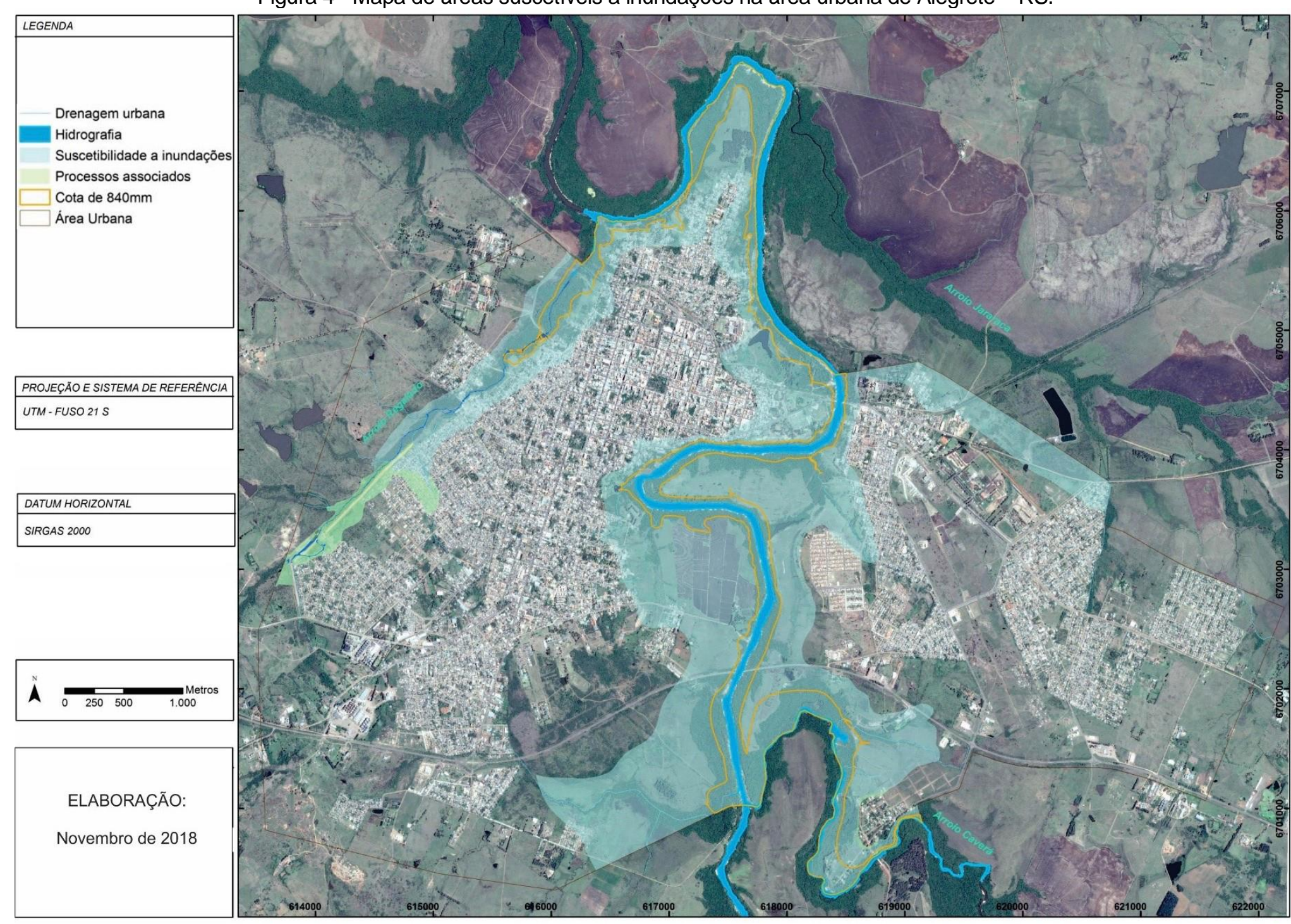

Fonte - os autores, 2018 
Figura 5 - Mapa de tempo de retorno para inundações na área urbana de Alegrete - RS.

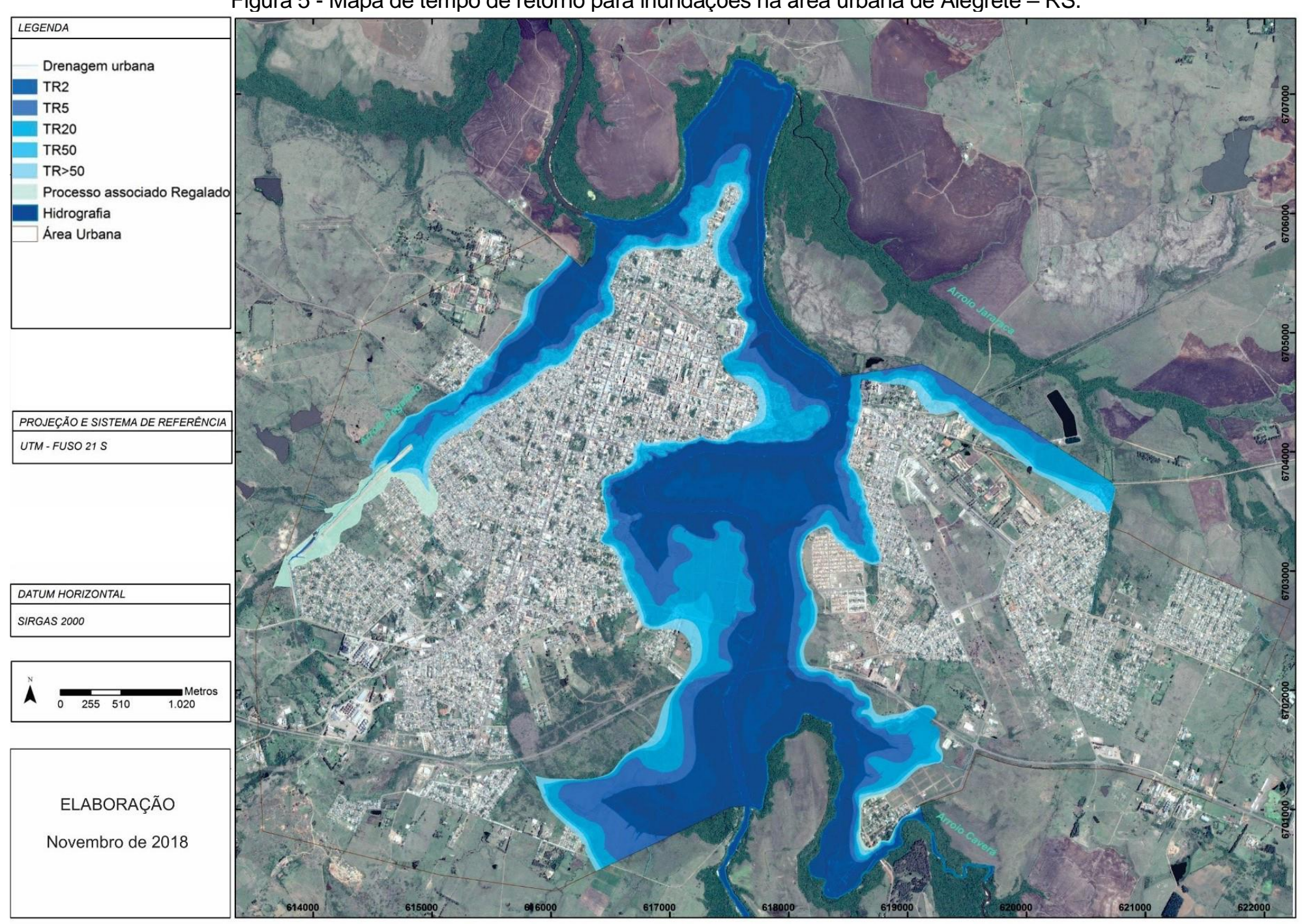

Fonte - os autores, 2018 
Observa-se que quase metade das áreas inundadas na área urbana de Alegrete estão relacionas a tempos de retorno de até 2 anos e avança para mais de $62 \%$ quando se considera um tempo de retorno de 5 anos. Essa área é atingida quando a régua linimétrica atinge a cota de 12,7 $\mathrm{m}$, o que equivale a altimetria de 79,2 m no terreno.

As áreas afetadas com tempo de retorno de 20 anos também, são expressivas, principalmente conforme pode ser observado a partir do mapa de tempos de retorno para inundações de Alegrete (Figura 5). Com esse tempo de retorno, 222 ha a mais são atingidos em relação a situação anterior, compondo em um total de 848,6 ha.

A área cujo tempo de retorno é mais elevado tem como característica o alcance de medidas linimétricas superior aos $14,4 \mathrm{~m}$, que corresponde a altimetria de $82 \mathrm{~m}$.

Os graus de perigo foram estabelecidos a partir dos tempos de retorno e as cotas que marcam estas inundações que indicam a severidade do processo.

Os índices foram estabelecidos para os seguintes tempos de retorno: TR2, TR5, TR20, TR50 e maior que 50 anos e a severidade das inundações para a área urbana de Alegrete esteve associada à altimetria de $71,83 \mathrm{~m}$ (correspondente à cota linimétrica de $5,34 \mathrm{~m}$, o menor valor dentre as máximas anuais registradas) e à altimetria de 81,7 $\mathrm{m}$ (linha de inundação medida). A amplitude destes valores $(9,92 \mathrm{~m})$ corresponde à amplitude do limite vertical de uma inundação e então a severidade deste processo.

A partir do mapa de áreas de perigo de inundação (Figura 6) pode-se observar como se distribuem as áreas ocupadas que se sobrepõem à suscetibilidade e estão sujeitas, de algum modo, aos processos relacionados à dinâmica hidrológica, sendo classificadas em diferentes graus de perigo.

O índice de perigo calculado para cada TR, a partir da metodologia proposta e em função destes critérios, e o respectivo somatório de áreas afetadas podem ser visualizados a partir da Tabela 3.

As inundações mais comuns (tempo de retorno de até 5 anos) afetam 5,3\% das áreas ocupadas, estabelecendo condições muito severas para as famílias que lá habitam, indicando situações de alto perigo. As áreas onde o grau de perigo é intermediário, com tempo de retorno de 20 anos, atinge $45 \%$ do total da área edificada que sofre eventos de inundação, mostrando que se trata de área com uma complexa gestão, pois afeta mais de 53 ha. A condição de perigo baixo é definida por áreas com tempo de retorno de 50 anos, atingindo $62,6 \%$ do total da área afetada e somente em condições muito extremas são atingidas áreas com tempo de retorno superior a 50 anos. Em geral, as áreas de perigo baixo e muito baixo, devido a menor severidade ou frequência, apresentam uma consolidada ocupação, estabelecendo uma coexistência de ocupação e inundações periódicas.

No arroio Regalado ocorrem processos específicos de barramentos no seu alto curso, que podem provocar inundações consideradas como de Perigo médio a alto baseado na recorrência.

Em relação aos bairros, essas áreas se estendem por 27 bairros e algumas áreas do centro da cidade são afetadas por diferentes níveis de inundação. As áreas ocupadas e sujeitas a inundações, que compreendem porções mais extensas, estão junto ao arroio Regalado, próximo à foz no rio Ibirapuitã, e estão representadas pelos bairros Canudos, Santo Antônio, Macedo, Izabel, Joaquim Fonseca Milano, Restinga, Vera Cruz (na margem leste) e Boa Vista (na margem oeste). A área do médio e alto curso estão associadas a processos menos severos, embora recorrentes, ocorrendo nos bairros Grande, Prado, Progresso e Sepé Tiarajú.

No setor montante à desembocadura do arroio Regalado, associadas ao rio Ibirapuitã, no setor norte da área urbana, são observadas áreas significativas nos bairros Rui Ramos e Vila Nova que são contíguas à margem oeste, afetando os bairros Tancredo Neves, Porto dos Aguateiros, Assunção, São João e, ainda, algumas residências no bairro Medianeira. Na porção leste, junto à margem direita do rio, são afetadas as áreas dos bairros Ibirapuitã, Oswaldo Aranha, Promorar Honório Lemos, Loteamento Ayrton Senna e margem esquerda do arroio Jararaca Capão do Angico e Centenário. Mais isolados e ao sul, os bairros Renascer e Balneário Caverá também são atingidos pelas inundações. 
Figura 6 - Mapa de perigo de inundações na área urbana de Alegrete - RS.

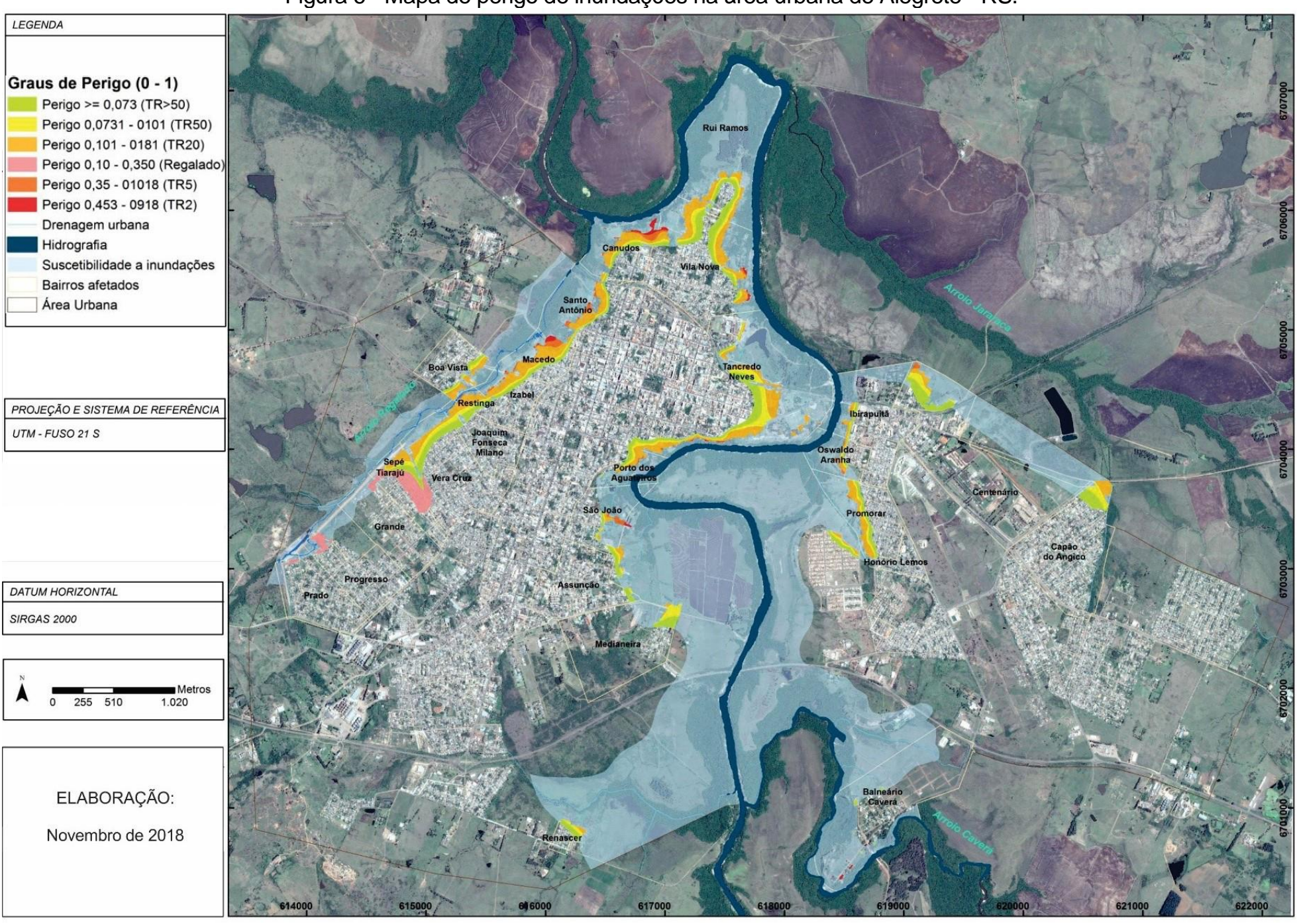

Fonte - os autores, 2018. 
Tabela 3 - Tempos de retorno associados à severidade e graus de perigo.

\begin{tabular}{c|c|c|c|c|c|c|c}
\hline $\begin{array}{c}\text { Tempo de } \\
\text { Retorno }\end{array}$ & $\begin{array}{c}\text { Cota } \\
\text { altimétrica } \\
(\mathrm{m})\end{array}$ & $\begin{array}{c}\text { Severidade } \\
(\mathrm{m})\end{array}$ & $\begin{array}{c}\text { Probabilidade } \\
\text { Excedência } \\
\text { Weibull }\end{array}$ & $\begin{array}{c}\text { Severidade } \\
\text { padronizada }\end{array}$ & $\begin{array}{c}\text { Graus de } \\
\text { Perigo }\end{array}$ & $\begin{array}{c}\text { Área } \\
\text { afetada (ha) }\end{array}$ & $\begin{array}{c}\text { Área } \\
\text { afetada (\%) }\end{array}$ \\
\hline TR 2 & 77,69 & 4,06 & 0,511 & 0,4093 & 0,918 & 1,94 & $1,6 \%$ \\
TR 5 & 79,19 & 2,56 & 0,198 & 0,2581 & 0,453 & 6,32 & $5,3 \%$ \\
TR 20 & 80,36 & 1,39 & 0,050 & 0,1401 & 0,186 & 53,61 & $45 \%$ \\
TR 50 & 81,01 & 0,84 & 0,019 & 0,0857 & 0,101 & 74,55 & $62,6 \%$ \\
TR $>50$ & Até 82 & $<0,84$ & 0,013 & 0,0645 & 0,073 & 110,49 & $92,7 \%$ \\
Processos & 82 ou mais & - & - & - & $0,1-0,35$ & 8,67 & $7,3 \%$ \\
associados & - & - & - & - & - & 119,16 & $100 \%$ \\
\hline Total & - & &
\end{tabular}

Fonte - Os autores, 2018.

\section{CONSIDERAÇÕES FINAIS}

O perigo de inundação está apresentado como processo, ação ou fenômeno que pode causar danos físicos, perda de vidas ou ferimentos, danos à propriedade, à perturbação social e econômica ou à degradação ambiental. $\mathrm{O}$ mapeamento de áreas de perigo de inundações tem sido viabilizado pelo emprego de um amplo conjunto de geotecnologias representado, principalmente, pelas informações derivadas do sensoriamento remoto e pelos Sistemas de Informações Geográficas (SIG's), que constituem ferramentas indispensáveis para esses mapeamentos.

O presente trabalho apresenta uma metodologia para determinar e cartografar as áreas de perigo, áreas suscetíveis a inundação que possam vir a gerar danos, na cidade do Alegrete.

Observa-se que em Alegrete as áreas sujeitas, de alguma forma, a processos de inundação, configuram a expressiva porção de $30,8 \%$ da área total da área urbana de Alegrete. Considerando as áreas efetivamente ocupadas, portanto áreas em condições de perigo, representam um pouco mais de $3 \%$. Esse número é importante, pois as inundações com tempo de retorno de 20 anos, atingem $45 \%$ do total da área edificada que sofre eventos de inundação, mostrando uma complexa gestão, pois afeta mais de 53 ha.

Dessa forma, o mapa de perigo funciona como a memória dos eventos históricos, podendo auxiliar os tomadores de decisão e a sociedade como um todo a empreender e fazer valer medidas de ordenamento territorial, com a finalidade de minimizar as consequências de eventos adversos futuros, reduzindo a intensidade dos desastres quando não for possível evitá-los.

\section{AGRADECIMENTOS}

O presente trabalho foi realizado com o apoio da Coordenação de Aperfeiçoamento de Pessoal de Nível Superior - Brasil (CAPES) - Código de Financiamento 001.

\section{REFERÊNCIAS}

ALEGRETE (município). Lei no 2.679, de 05 de junho de 1996. Plano diretor do município de Alegrete. Disponível em: <http:/www.alegrete.rs.gov.br>: Acesso em: 10 de jan. 2016.

ASHTECH. GNSS Solutions ${ }^{\circledR}$ - V. 3.80.8. Fort Worth, TX, 2006.

BRASIL. Estatuto da Cidade (Lei no 10.257, de 10 de julho de 2001). Diário Oficial da União - Seção 1. Câmara dos Deputados - Palácio do Congresso Nacional, Brasília - DF. Seção 1 - Eletrônico - 11/7/2001. 
BURTON, I., R. W. KATES, G. F. WHITE. The Environment as Hazard. New York: Guilford Press,1993. $290 \mathrm{p}$.

CASTRO, A. L. C. Glossário de defesa civil, estudo de riscos e medicina de desastres. 2. Ed. Brasília: Ministério do Planejamento e orçamento, 1998.

CUTTER, S.; BARNES, L. R.; BERRY, M.; BURTON, C. G. A place-based model for understanding community resilience to natural disasters. Global Environmental Change, n. 18, p. 598-606, 2008. https://doi.org/10.1016/j.gloenvcha.2008.07.013

ECKHARDT, R. R. Geração de modelo cartográfico aplicado ao mapeamento das áreas sujeitas às inundações urbanas na cidade de Lajeado/RS. UFRGS. 2008. Disponível em: $<$ http://www.ufrgs.br/srm/ppgsr/publicacoes/Dissert_RafaelEckhardt.pdf>.

ESRI. GIS Mapping Software, Spatial Data Analytics \& Location. ESRI, 2012. Disponível em: $<$ https://www.esri.com/en-us/home>

JULIÃO, R.P.; NERY, F.; RIBEIRO, J.L.; BRANCO, M.C.; ZÊZERE, J.L. Guia Metodológico para Produção de Cartografia Municipal de Risco e para Criação de Sistemas de Informação Geográfica (SIG) de base Municipal. Porto/Portugual: Autoridade Nacional de Proteção Civil. 2009.

KUSKY, T. Floods: hazards of surface and groundwater systems. (The Hazardous Earth Set, 8 Volume). Facts On File, 2008.144p.

MARANDOLA JUNIOR., E. HOGAN, D.J. Natural hazards: o estudo geográfico dos riscos e perigos. Ambiente \& Sociedade, Campinas, ANPPAS, v.7, n.2, p.95-109, jul./dez. 2004. https://doi.org/10.1590/S1414-753X2004000200006

MENEZES, D. J.; SCCOTI, A. A. V. Inventário de registro de inundações no estado do Rio Grande do Sul entre 1980 e 2010. In: Luís Eduardo de Souza Robaina; Romário Trentin. (Org.). Desastres Naturais no Rio Grande do Sul. Editora da UFSM, 2013, v. 1, p. 163-179.

REBELO, F. Um Novo Olhar Sobre os Riscos? O Exemplo das Cheias Rápidas (Flash Floods) em Domínio Mediterrâneo. Territorium, v. 15, p. 7-14, 2008. https://doi.org/10.14195/1647-772315 1

ROBAINA, L.E.S.; SCHIRMER, G. J.; KORMANN, T. C. Zoneamento das inundações na área urbana de Alegrete - Rio Grande do Sul - Brasil. Geociências (São Paulo. Online), v. 32, p. 378-387, 2013.

UNITED NATIONS INTERNATIONAL STRATEGY FOR DISASTER REDUCTION - UNISDR. Terminology on Disaster Risk Reduction. International Stratergy for Disaster Reduction (ISDR), p. 130, 2009. Disponível em: <www.unisdr.org/publications>.

WESTEN, C.J.; VAN ASCH, T.W.J.; SOETERS, R. Landslide hazard and risk zonation: why is it still so difficult?. Bulletin of Engineering Geology and the Environment, 2006. p. 167 - 184 . https://doi.org/10.1007/s10064-005-0023-0

Recebido em: 20/08/2019

Aceito para publicação em: 21/02/2020 